\title{
INTERESTS, IDENTITIES, AND RELATIONS: DRAWING BOUNDARIES IN CIVIC ORGANIZATIONAL FIELDS*
}

\author{
Mario Diani and Katia Pilati ${ }^{\dagger}$
}

This article combines social movement and organizational theory to explore boundary definition in civic organizational fields. Drawing upon evidence from two British cities and applying network analysis to relations between organizations interested in environmental, ethnicity, and migration issues, we show that identities shape network patterns more consistently than interest in specific issues. While this finding supports previous insights from organizational and social movement research on the relation between identities and fields, we go beyond them in showing that the role of identities is pivotal regardless of the nature of local political opportunity structures and cultures. We conclude by discussing possible strategies for exploring the link between organizational and social movement fields.

Although the study of social movements as organizational fields has a long history (Curtis and Zurcher 1973), many have recently claimed that this perspective has not been developed fully (McAdam and Scott 2005; Minkoff and McCarthy 2005; Zald 2008; Fligstein and McAdam 2011). Additionally, Minkoff and McCarthy (2005: 291) have argued that any attempt to seriously elaborate the connection between social movements and organizational fields should start with "a descriptive step, namely determining the boundaries and contents of the field of action: Who are the players? How are they connected?"

Consistent with Minkoff and McCarthy's (2005) call, we take a primarily descriptive approach in this report, yet one which enables us to explore a key problem for our understanding of organizational fields - namely, the extent to which organizational interests and identities correspond to relational patterns within organizational fields. This approach goes to the heart of how the boundaries of organizational fields are defined. We do not infer the existence of a field from the presence of actors that share certain properties like an interest in a determined set of issues, or who define themselves by a set of shared problems. Rather, we conceive of fields as sets of actors characterized by high relational density and actors' reciprocal recognition. In this framework, our aim is to explore the extent to which issue interests and organizational identities affect organizational networks in two different British cities. We draw on evidence collected among civic organizations between 2001 and 2002 in two British cities, Bristol and Glasgow, acting in four main domains: (1) environmental issues, (2) issues related to ethnicity and migration, (3) community issues, and (4) social exclusion.

\footnotetext{
* This article originates from a project on "Networks of civic organisations in Britain" that Mario Diani conducted with Isobel Lindsay (University of Strathclyde in Glasgow) and Derrick Purdue (University of West of England, Bristol) from June 2000-September 2003. The study was part of the Democracy and Participation Program, funded by the Economic and Social Research Council (contract L215 25 2006). We thank program director Paul Whiteley for his constant support, and research assistants in Glasgow and Bristol for their work on data entry and data collection. Giuseppe Sciortino, Veronica Benet-Martinez, and two anonymous referees provided careful readings of our text. We are also grateful to participants in seminars at the Instituut voor Migratie en Etnische Studies, Universiteit van Amsterdam (March 2005), the Annual Meeting of the American Sociological Association (Montreal, August 2006), and the Equalsoc Summer School (Levico, July 2007) for their comments on earlier drafts.

${ }^{\dagger}$ Mario Diani is ICREA Research Professor in the Department of Political and Social Sciences at the Universitat Pompeu Fabra. Katia Pilati is a FRS-FNRS Research Fellow at GERME-Institut de Sociologie of the Université Libre de Bruxelles. Please direct all correspondence to mario.diani@upf.edu.
} 


\section{ORGANIZATIONAL FIELDS AS INTERACTION SYSTEMS}

An organizational field consists of organizations that, in the aggregate, represent a recognized area of institutional life (DiMaggio and Powell 1991: 64-65; Martin 2003). More specifically, we may conceive of fields as networks, whose structure largely depends on levels of interaction, patterns of domination and cooperation, the exchange of information, and mutual awareness among participants (DiMaggio and Powell 1991: 65). Although relational patterns may become institutionalized, the existence of a field ultimately depends on actors' reciprocal recognition. In other words, a field is an intersubjectively organized construct entailing the reciprocal recognition of active organizations, carriers of certain identities and interests, as well as dispositions to act and relate (Bourdieu 1994; Lamont and Molnar 2002: 186-188; Martin 2003).

This view of fields as settings where actors frame their action vis-à-vis one another is highly consistent with dominant views of social movements in terms of two dimensions related first to interactions among actors and second to actors' shared collective identities. ${ }^{1}$ Whether we treat them as "sustained interactions" between challengers and power holders (Tilly 1978, 2005), or as networks of individuals and/or organizations sharing a distinctive collective identity (Diani 1992; Diani and Bison 2004), social movements are based on repeated interactions between multiple actors that gradually come to elaborate distinctive representations of the world and of themselves. Already in the 1980s, Melucci (1989) explicitly spoke of social movements as action systems, in which identities defined the boundaries and were subject to recurrent negotiation. Developments in the analysis of fields have been highly consistent with those insights. Many have stressed the competitive and confrontational nature of fields as dynamic entities in which access is subject to negotiation and conflict, launching a bridge between the two strands of research (for recent variations on this theme see Fligstein 2001; Crossley 2002: 178-183; Henson 2003; Lounsbury, Ventresca, and Hirsch 2003; Armstrong 2005; Fligstein and McAdam 2011).

Our focus here is on how organizational interests (or "issue agendas" or "issue priorities") and organizational identities shape interactions and generate areas of high relational density within larger organizational populations. ${ }^{2}$ We do not propose an opposition between instrumental, objectified mechanisms reflected in the concept of interests, and a cultural, symbolic set of mechanisms expressed by the concept of identity (or, better, identities). To the contrary, a symbolic dimension inheres to any social tie, including those normally represented as instrumental (Mische 2003). As a matter of fact, a boundary - identified either by shared interests or identities - displays two dimensions: a symbolic dimension referring to actors' social classification and collective representation, and a social or behavioral dimension referring to "everyday networks of relationships that result from individual acts of connecting and distancing" (Wimmer 2008: 975; see also Tilly 2005).

When we refer to "organizational identities" we have in mind broader representations of actors' position in relation to other actors and to broader representations of social life than those associated with issue agendas. Since the late 1990s, network analytic approaches have paid increasing attention to the role of identity and cultural dynamics within fields (Mohr and Duquenne 1997; Lomi and Larsen 2001; Rao, Monin, and Durand 2003; Breiger and Mohr 2004). However, these developments have largely — if not entirely — bypassed social movement analysis. While social movement analysts have been referring to "identity" at least since the 1980s, they have mainly viewed it as the link between individuals and collectivities, with special attention to recruitment processes. ${ }^{3}$ They have also often treated identity as a specific point of conflict in relation to various forms of "identity politics" or "new social movements," or as a strategic tool available to specific organizations (for literature reviews see Polletta and Jasper 2001; Hunt and Benford 2004). In contrast, despite a few major exceptions (Melucci 1989, 1995; Mische 2003), identity mechanisms have rarely been associated with the definition of boundaries of organizational populations (Polletta and Jasper 2001: 295-96; Hunt and Benford 2004: 441-44). 
In what follows we focus on how identity mechanisms interact with interests in shaping networks of voluntary organizations. Here, the tensions between actors' self-definitions and definitions provided by other actors when categorizing organizations are of paramount importance. Identity is generated through interactive mechanisms involving actors and their social environment (Stryker, Owens, and White 2000; Ellemers, Spears, and Doosje 2002). Whether we refer to them as "internal recognition" (Pizzorno 1996), "self-identification" (Brubaker and Cooper 2000), or "self-directed identity" (Melucci 1989), self-definitions of identity contribute to a distinctive understanding of reality by linking single actors to wider groups. They are matched to a variable extent by external actors' categorizations, from time to time defined as "external recognition" (Pizzorno 1996), "categorical imposition" (Bourdieu 1994), "categorization or external identification" (Brubaker and Cooper 2000), or "heterodirected identity" (Melucci 1989). ${ }^{4}$ In this case, recognition is not as much the outcome of an active search for meaning as it is the passive reception of classifications imposed by others, a process of attribution in which other actors are active subjects (Pizzorno 1996: 124). Categorization can become institutionalized through specific political processes, but it can also originate from more contingent situations concerning, for example, actors' mutual definition in daily interactions (Brubaker and Cooper 2000; Tilly 2005).

Defining one organization as part of a broader collectivity is not easy, regardless of whether the definition comes from the actors themselves or from external observers. For example, antinuclear coalitions, local anti-road groups, and voluntary associations promoting the conservation of the natural landscape or historic buildings may or may not define themselves (and/or be defined) as environmentalist. It is a long way from middle-class nimbyism to environmental justice direct action, or from animal rights activism to conservation activity (Rootes 2003). At the same time, however, shared basic values and widely agreed upon issues may facilitate the establishment of shared collective identities, even if with variable emotional power (Dalton 1994; Diani 1995).

The classifications in relation to ethnicity and/or claiming to act on behalf of ethnic groups are even more problematic. Ethnic identities are surely based on distinctive traits, traceable in history, culture, language, lifestyles, etc. (Hutchinson and Smith 1996). However, while those traits may strengthen identification with specific groups, those feelings are not easy to translate to the overall ethnic minority sector. A collective identity for ethnic communities, capable of sustaining joint action in the public sphere, is something to be constructed rather than found "out there." Different groups may surely push forward a common agenda of multiculturalism, minority empowerment, human rights, and antiracism; but they may similarly — and perhaps more easily - fail to build cross-cutting, broader collective identities linking them together and instead revert to inward-looking and social closure strategies based precisely on differences among ethnic groups such as cultures, traditions, or religions.

The saliency of shared interests and identities in shaping interorganizational networks may also be affected by the characteristics of the political context where organizations operate. In other words, the political context may mediate the impact of interests and identities over organizational fields. When referring to the political context, we differentiate neatly between political opportunity structures, defined in terms of access to policy making, and contextual factors such as pre-existing cleavages or political cultures. On the side of public policies and institutional arrangements, by creating opportunities of access to resources, public authorities and established political actors may indeed encourage otherwise distant ethnic and/or cultural groups to develop a sense of commonality and, ultimately, also engage in distinctive and relatively dense interaction patterns.

While the opening of opportunities has certainly facilitated the emergence of environmentalism as a major, large scale political and cultural actor (Rootes 2003), its consequences on ethnic and minority political actors might have been even more impressive. Scholars have shown how political contexts affect immigrants and minorities' organizational networks (Vermeulen 2006), and there have also been considerable efforts to identify minorities as a specific area of policy. In Britain, ethnicity is regularly constructed as a category bringing 
together a number of diversified social groupings. This applies to government bodies predisposed to deal with racial affairs, such as the Commission for Racial Equality, to specific legislation such as the Race Relations Acts of 1965 and 1976, as well as to research bodies, that often use "Black and Minority" as the keywords to denote a specific sector of the population (Modood 2005).

In the UK, while minority or migrant communities remain most of the time strongly organized around their specific cultures and traditions, there have been many attempts at collaboration across boundaries, with varying levels of institutionalization (from umbrella organizations such as the Black Development Agency or the local Minorities Networks to the Black Environmental Network, an attempt to mobilize minority members on environmental issues). This means it is sensible not only to think of the ethnic field as distinctive in terms of common interests, but also to conceive of an identity (even a movement identity) linking those sharing a certain condition and/or certain concerns. This becomes even more evident if we take into account the possible overlap between ethnic issues and migrants' rights issues (and human rights issues more generally). In other words, the fact that institutions recognize environmental or ethnic issues as distinctive categories might encourage organizations acting on those issues to regard themselves as part of larger, even if vaguely defined, collectivities, associated under the same broad headings. Accordingly, this should also encourage denser patterns of in-group relations.

However, while opportunities of access to resources for collective actors may facilitate the formation of broader collective identities and alliances, they may also encourage a division of labor and/or competition between organizations and therefore discourage the development of dense relations. The presence of opportunities for access and representation for both the ethnicity and migration and the environmental sector, and their involvement in policy making and policy implementation, might indeed reduce the salience of both identities. Specialization, niche building, and professionalization might indeed replace the activism that so much relies upon the mobilizing role of identity. For the same reasons, the choice of allies by civic organizations might follow largely pragmatic lines, and the boundaries of networks might be shaped primarily by the issue agendas that attract the most attention among local organizations.

Other fundamental contextual factors - namely, the salience of established cleavages - may also have important consequences for boundary emergence. Such cleavages may legitimize claims to public recognition for groupings that are defined by more vague and inclusive criteria than those associated with specific environmental or ethnic profiles and/or backgrounds and increase their likelihood to ally. In polities where cleavages, in particular the class cleavage, are still salient, there will be limited chances that interests and identities, which somehow crosscut main lines of political differentiation, will define new boundaries within organizational fields (Kriesi, Koopmans, Duyvendak, and Giugni 1995). More specifically, the salience of issue agendas, as well as of identities, that may be more easily framed in terms of inequality and exclusion (such as ethnicity and migration), might be higher in polities with a political culture closer to the class cleavage. To the contrary, where traditional cleavages are increasingly pacified there should be better chances for the development of other types of boundaries based on identities and/or issue agendas closer to new issues and/or identities (of which the environment is certainly one major example). ${ }^{5}$

\section{ENVIRONMENTALIST AND ETHNIC-MINORITY FIELDS}

The data used in this article was collected between 2001 and 2002 in the context of a broader project on networking by citizens' organizations in local settings in two British cities, Glasgow and Bristol. As resource limitations prevented us from mapping the whole civic sector, ${ }^{6}$ we focused on participatory organizations promoting advocacy and interest representation on environmental, ethnic and minority, community, and social exclusion issues. We chose these 
issues because they were distinctive enough to be the object of specific action by specific organizations, but were also compatible enough to allow for the smooth development of broader coalitions in case organizations had been willing to do so.

Face-to-face interviews were conducted with representatives of 124 organizations in Glasgow and 134 in Bristol, all of which differed substantially in terms of size, length of existence, formalization, and resource levels commanded (see table 1). We selected two types of organizations: those that, according to our informants, ${ }^{7}$ played a significant role at the city-level (and possibly in broader arenas as well), and those that were influential at the community level. The latter were located in relatively deprived areas of the two cities: the Southside in Glasgow, which historically featured a massive working-class presence, including neighborhoods such as Govan, Govanhill, Gorbals, and Pollokshields; and in Bristol, the area including Easton, Knowles, Withywood, and Hartcliffe neighborhoods, characterized by a strong presence of ethnic minorities. Organizations not included in our original list but named as important partners at least three times were also interviewed. This data collection strategy makes us confident that all the most central organizations in the two cities were contacted. ${ }^{8}$

Table 1. Organizational Traits in Bristol and Glasgow ${ }^{\mathrm{a}}$

\begin{tabular}{|c|c|c|c|}
\hline Variable Descriptions & Values / Categories & $\begin{array}{c}\text { Bristol } \\
(\mathrm{N}=134)\end{array}$ & $\begin{array}{l}\text { Glasgow } \\
(\mathrm{N}=124)\end{array}$ \\
\hline $\begin{array}{l}\text { Researchers' classification of } \\
\text { civic organizations }\end{array}$ & $\begin{array}{l}\text { Environment } \\
\text { Ethnic minorities and migrants } \\
\text { Community } \\
\text { Social exclusion }\end{array}$ & $\begin{array}{l}27 \\
19 \\
28 \\
25\end{array}$ & $\begin{array}{l}16 \\
28 \\
23 \\
33\end{array}$ \\
\hline Interest in issues $(0-100 \text { scales })^{b}$ & $\begin{array}{l}\text { Social exclusion } \\
\text { Environment } \\
\text { Ethnicity and migration } \\
\text { Globalization } \\
\text { Housing }\end{array}$ & $\begin{array}{l}40 \\
31 \\
25 \\
22 \\
26\end{array}$ & $\begin{array}{l}50 \\
28 \\
41 \\
23 \\
47\end{array}$ \\
\hline Scale of activity & $\begin{array}{l}\text { Neighborhood } \\
\text { City-wide } \\
\text { Regional } \\
\text { National or broader }\end{array}$ & $\begin{array}{l}27 \\
40 \\
18 \\
15\end{array}$ & $\begin{array}{l}27 \\
32 \\
21 \\
20\end{array}$ \\
\hline Years of activity in 2002 & $\begin{array}{l}1-5 \\
6-10 \\
11-20 \\
20+\end{array}$ & $\begin{array}{l}24 \\
21 \\
34 \\
21\end{array}$ & $\begin{array}{l}32 \\
15 \\
24 \\
29\end{array}$ \\
\hline Number of registered members & $\begin{array}{l}0 \\
1-1,000 \\
1,000+\end{array}$ & $\begin{array}{l}27 \\
62 \\
11\end{array}$ & $\begin{array}{l}44 \\
44 \\
12\end{array}$ \\
\hline $\begin{array}{l}\text { Number of paid staff members } \\
\text { (full and part-time) }\end{array}$ & $\begin{array}{l}0 \\
1-5 \\
6-20 \\
20+\end{array}$ & $\begin{array}{l}30 \\
22 \\
36 \\
12\end{array}$ & $\begin{array}{l}35 \\
35 \\
16 \\
14\end{array}$ \\
\hline Budget & $\begin{array}{l}\text { Up to } £ 10,000 \\
£ 10,000 \text { to } £ 99,999 \\
\text { Over } £ 100,000\end{array}$ & $\begin{array}{l}30 \\
26 \\
44\end{array}$ & $\begin{array}{l}31 \\
35 \\
34\end{array}$ \\
\hline Level of formalization ${ }^{c}$ & $\begin{array}{l}\text { Low }(0-3) \\
\text { Medium (4-6) } \\
\text { High (7-9) }\end{array}$ & $\begin{array}{l}25 \\
55 \\
20\end{array}$ & $\begin{array}{l}21 \\
43 \\
36\end{array}$ \\
\hline
\end{tabular}

Notes: ${ }^{a}$ All numbers are percentages unless otherwise indicated. ${ }^{\mathrm{b}}$ See Diani (2005: 62) and footnote 14 for details on scale construction. ${ }^{c}$ Additive index based on nine indicators reflecting the presence of: chairperson, board of directors, executive and/or special committee, secretary, treasurer, written constitution, general assembly, and charity status (Cronbach's Alpha $=0.70$ ). 
Our analyses focus on alliance ties. In order to identify all the meaningful collaborations in which organizations were involved, we took a two-step approach. The first step relied on respondents' spontaneous recollection of "up to five groups/organizations with which you collaborate most intensely." The next step entailed partial prompting as respondents were also asked, later in the interview, whether they had connections that implied sharing core members or promoting joint projects to voluntary groups active in any of the following categories: environmental groups, ethnic minority and migrants organizations, community organizations, unions and other economic interest groups, religious organizations, political parties, other political organizations, other voluntary associations, or any other organization. Participation in a formally constituted organization, coordinating a number of different groups on a specific campaign, was recorded as an interorganizational tie, similarly to an alliance between two any other formally independent organizations.

We did not measure the intensity of the ties, but merely their presence or absence, as it has been repeatedly shown that respondents' accuracy in recording the presence of a tie is not usually matched by a similar accuracy in reporting about its intensity (Marsden 1990, 2005). Moreover, we were most interested in identifying the alliances that each organization regarded as meaningful rather than in contrasting intensity or frequency of interaction, which is by definition strongly dependent on other factors such as organizations' overall size or perceived influence. ${ }^{9}$ Accordingly, our data reflect how organizations perceive their social space and identify their relevant contacts within it. The choice of not restricting the analysis to the "most intense" ties and to include instead also what may be relatively weak ties is consistent with our focus on organizational fields. By definition, they consist of all the organizations relevant to a recognized domain of social life, not only of the most strongly connected ones (DiMaggio and Powell 1991: 64). ${ }^{10}$

Bristol and Glasgow provide an interesting opportunity for comparison because of their mix of similarities and differences. In the years preceding our research they had seen similar developments towards a service-based economy. ${ }^{11}$ Since the closure of the docks and most of the heavy industry in the 1960s and 1970s, working-class presence in both cities had diminished steadily, with employment in the manufacturing industry in the early 2000s accounting for about 10 percent of the workforce in Glasgow and 11 percent in Bristol. ${ }^{12}$ Bristol had a stronger presence of professional bourgeoisie and highly qualified white-collar workers. Its main employers were high-tech firms like those in the aeronautic industry, firms in the service sector, especially the financial sector, and big public employers such as the Ministry of Defense. This is reflected in a population with a higher proportion of degree holders and professionals/managers than in Glasgow ( 25 percent vs. 18 percent and 28 percent vs. 21 percent respectively). Bristol was also significantly more affluent than Glasgow. At the start of the new millennium, unemployment rates were higher in Glasgow than in Bristol (5 percent vs. 3 percent), with long term unemployment in particular representing a major problem (37 percent of the unemployed vs. 25 percent in Bristol). Housing was another major issue, with 39 percent of the population still living in council flats (vs. 21 percent in Bristol) and 17 percent living in homes with no central heating (vs. 9 percent).

There were, however, differences in the ethnic composition of the two cities, which was - and still is - larger and more diversified in Bristol. Over 8 percent of the 2001 residents were born outside the UK, with some neighborhoods approaching 20 percent of minority residents, vs. 5 percent in Glasgow. Both the Asian and the Black (mostly Afro-Caribbean) community are well represented in Bristol (2.8 and 2.3 percent respectively). In contrast, Black communities were hardly present in Glasgow, where Pakistanis are the dominant minority group, outnumbering the Indians and the Chinese by two to one.

The political profile of the two cities shows both important similarities and some remarkable differences. Despite institutional differences between England and Scotland, both cities experienced the increase in opportunities for formal institutional access, brought about by New Labour since the late 1990s, the trends towards the professionalization of the 
voluntary sector and its growing involvement in policy design and implementation, usually in partnerships with business and local government (Lowndes, Pratchett, and Stoker 2001; Taylor 2003). In both cities, opportunities opened up for participation through institutional channels, although this was often perceived as a limitation to the autonomy of action of the voluntary and community sector (Gilchrist 2000).

While the two cities were similar in terms of opportunities for access to the local political system, they differed more pronouncedly in their political cultures. In Glasgow, persisting deprivation has facilitated the continuing central role in local politics of working class and left-wing labor politics, while the strength of the Pakistani community compared to other minority groups has also encouraged and reproduced their integration in the Labour political machine. One should also remember the role of the center-periphery (Nationalist) cleavage and the religious (Protestant vs. Catholic) cleavage in fostering a polarized political culture. City politics in Bristol have also been dominated by Labour since the 1980s (at least until the May 2003 local elections), but the overall profile of the city is very different, with a history of swings between Labour and Tories in the context of an overall moderate political culture.

Pooled data for the two cities from the four waves of the British Social Attitudes survey covering the years in which this project was conducted (2000-2003) illustrate differences in the role of Labour relative to other political parties. While the share of Labour sympathizers was fairly similar (50 percent in Glasgow as opposed to 46 in Bristol), the ratio of Labour supporters to supporters of other major parties was drastically different in the two cases: they outnumbered Conservative supporters by fourteen to one in Glasgow, and by two to one in Bristol, and Liberal-Democrat supporters by ten to one in Glasgow, and by four to one in Bristol. Glasgow had been a stronghold of left-wing political groupings critical of the Labour party (including, at the time of the project, and most successfully, the Scottish Socialist Party). Similar groups had never achieved organizational strength in Bristol despite a small, very active community of radical activists, independent from any formal organization. A distinctive trait of Bristol civic culture was what one of the activists interviewed for this project described as a "laid-back political culture" - that is, a style of politics in which radical polarization along major class divides came second to the concerted attempts to mediate between multiple interests.

\section{DEFINING THE BOUNDARIES OF ETHNIC AND ENVIRONMENTAL FIELDS}

In the following analyses we aim to explore how interests and identities shape organizational ties, and therefore organizational field boundaries, by applying network analysis. As far as identities are concerned, we test both the role of self-defined identities of organizations and the impact of collective identities. Specifically, we ask if organizations with similar interests or identities have higher probabilities to connect with each other than to connect with organizations with different interests or identities. ${ }^{13}$

We define fields as sets of organizations with similar issue interests. Anyone with more than a passing interest in ethnic or environmental issues might be regarded as part of the ethnic or environmental field. In order to test whether issue agendas shape the structure of interactions within local civic networks, we differentiated between organizations having multiple interests in problems that might be linked to either environmental and/or ethnicmigration issues. Environmental themes included pollution, nature conservation, waste, energy, environmental education, farming, forestry, fishing, science and technology, food, transport, genetically modified food, animal welfare, tourism, and building conservation. As for ethnic and migration issues, the list included racial harassment, minority citizenship rights, minorities' access to public office, multiculturalism, asylum seekers, minority entrepreneurship, and independent education for minorities. ${ }^{14}$ In both cases we assumed that organizations that had expressed an interest in at least two themes could be considered as having more than 
a passing interest in the broader issue. By this measure, we found 78 organizations in Glasgow and 56 associations in Bristol that were interested in ethnic issues (more than half of Glaswegian organizations and more than 40 percent of Bristolian ones), while 68 organizations in Glasgow and 72 in Bristol turned out to be interested in environmental issues.

How well do these categorizations affect interaction patterns? In other words, do organizations sharing strong interests in sets of issues interact more frequently among themselves than with others? And do the political opportunity structures and the political cultures in Glasgow and Bristol mediate the impact of sharing strong interests on organizational alliances? The most straightforward way to address this question, and the most easily intelligible for readers who are not particularly familiar with network analysis, is by means of relational contingency tables and odds ratios. The only difference to standard contingency tables lies in the means of testing the significance of the differences across groups, which is based on randomized permutations instead of on the standard chi-square distribution (Borgatti, Everett, and Freeman 2002; Hanneman and Riddle 2005: 306-08). The effect of the political context on the probability that shared interests shape interorganizational alliances is explored by providing separate analyses for the two cities.

Table 2 reports for both cities and for both issues the number of ties that were found between organizations sharing similar levels of interest and between organizations with different levels of interest. For example, 66 ties were found in Glasgow between organizations with a low interest in environmental issues vs. 134 ties among organizations with high interest. Moreover, organizations with low environmental interests were more likely to identify organizations with high interests as alliance partners (91 ties sent from low to high interest organizations) than the other way around (only 61 ties). Figures in brackets represent the ratio between the actual number of ties and what should be expected under conditions of independence. As we can see, there is a slight over-representation of ties among organizations with high interest (1.27), not enough to suggest that environmental issues have a structuring effect on Glasgow civic networks. The chance that ties develop between organizations with similar levels of interest, reflected in the odds ratios, is only 2.4 higher than that of ties occurring between organizations with different levels of interest. Differences in the distribution of ties are not statistically significant $(\mathrm{p}=.144)$. The situation is different in Bristol, where odds ratios of 6.6 and a probability of nonrandom results below .001 suggest interest in environmental issues do have a significant impact on local civic networks. If we move to con-

Table 2. Distribution of Alliance Ties among Organizations, by Interest in Environmental and Ethnic and Migrants Issues (observed/expected ratios in brackets)

\begin{tabular}{lcccc}
\hline \hline Environmental Issues & \multicolumn{2}{c}{ Glasgow } & \multicolumn{2}{c}{ Bristol } \\
\hline & Weak Interest & Strong Interest & Weak Interest & Strong interest \\
Weak interest & 66 & 91 & 60 & 33 \\
& $(.93)$ & $(1.04)$ & $(1.08)$ & $(.50)$ \\
Strong interest & 61 & 134 & 35 & 134 \\
& $(.69)$ & $(1.27)$ & $(.53)$ & $(1.78)$ \\
& Odds ratio 2.4 & $\mathrm{p}=.144$ & Odds ratio 6.6 & $\mathrm{p}=.000$ \\
\hline \multirow{2}{*}{ Ethnic and Migrants Issues } & \multicolumn{3}{c}{ Glasgow } & \multicolumn{2}{c}{ Bristol } \\
\hline & Weak Interest & Strong Interest & Weak Interest & Strong interest \\
Weak interest & 44 & 51 & 97 & 56 \\
Strong interest & $(.92)$ & $(.62)$ & $(1.10)$ & $(.87)$ \\
& 71 & 186 & 49 & 60 \\
& $(.86)$ & $(1.34)$ & $(.76)$ & $(1.33)$ \\
\hline \hline
\end{tabular}

Note: $\mathrm{N}=134$ in Bristol; $\mathrm{N}=124$ in Glasgow. 
sider the impact of interest in ethnicity and migration issues, the situation is reversed: differences in interest in those issues appear to exert a significant if relatively weak influence in Glasgow, with a distribution significant at the .05 level and odds ratios at 1.6 while they are not significant in Bristol $(\mathrm{p}=.12)$.

These findings can be read in two very different, yet similarly plausible ways. We may find it surprising that the propensity of organizations strongly interested in a set of issues to engage mainly in alliances among themselves is not consistently significant across the board. After all, we are contrasting ties between organizations devoted to issues that, for all their complexity, are relatively easy to identify, with ties involving organizations that are interested in much broader - and therefore less focused - sets of issues (all those "nonenvironmental" or "non-ethnic"). This fact alone should lead to similarity in issue agendas playing a structuring effect in both cities and both issue domains. However, this is not the case.

From a different point of view, we might find it striking that issue agendas play any role at all. If we consider the overwhelming emphasis placed on the importance of identities in shaping the boundaries of fields in both the organizational and the social movement literature, a very inclusive measure of interest in quite broadly defined issues should not affect the specific relational patterns. Why, then, are some issue agendas salient? One could think that this depends on the relevance of certain issues in specific local polities. In contexts characterized by open opportunities of access, differences in levels of interest in issues might translate automatically into differences in relational patterns. Thus, the most popular issues in the local civic scene would shape interaction patterns in a more pronounced way. However, while Glaswegian organizations are more interested than Bristolian ones in ethnic issues, interest in environmental issues is similar in the two cities (see table 1). Our suggestion that the presence of opportunities for participation in local policy making result in organizational fields being shaped by the most diffuse issue priorities among local organizations finds only partial support from our data. It works for ethnic and migrants' issues that attract significantly more interest in Glasgow than in Bristol (see table 1) and shape the organizational field in the former (see table 2), but not for environmental issues that are similarly popular in both cities (see table 1) but only shape the civic network in Bristol (see table 2).

We get more consistent accounts of the capacity of issues to shape local civic sectors if we look at the role of local political cultures. In Glasgow, the strong tradition of working class militancy and the attention for material, redistributive issues may have assigned greater relevance to ethnicity and migration issues than to environmental ones. In principle, even the former might be articulated, placing a strong emphasis on identity politics and issues of difference rather than on equality of access to material rewards. In practice, however, this has rarely happened in Glasgow. Even the biggest Asian community (Pakistani) has been traditionally represented by the Labour party. Moreover, at the time of the survey, migration issues were central in the city, covering a broad range of issues from the strictly material (in particular, housing) to human rights (for example, the mobilization against the detention center for asylum seekers in nearby Dungavel). Therefore, ethnicity and migration issues seem to align more easily than environmental ones with the dominant political cleavages in the city.

In contrast, Bristol is a city where material, redistributive conflicts have traditionally played a more limited role; where the ethnic groups scene is more diversified and not so neatly associated with Labor and unions as in Glasgow; and where some among the most likely and most vocal advocates of those issues - new left groups broadly defined - are relatively weak by comparison to the West of Scotland (Bull and Jones 2006). In that context, the chance for ethnicity and migration issues to shape the city's networks altogether might well be limited. On the other hand, the salience of environmental issues in that context is consistent with the long established association between the city - and in general the South-west of Englandand various forms of environmental practices, on both the political and, most frequently, the cultural side. Indeed, even the impact of new social movements in Bristol has mostly been at the cultural level (Purdue, Dürrschmidt, Jowers, O'Doherty 1997; Anderson 2004). 
Our exploration suggests that the salience of environmental issues in Bristol and ethnicity and minority issues in Glasgow might be related to the greater salience of the class cleavage in the latter, and the relevance of "new politics" in the former. At this level, a relation seems to connect the characteristics of local political cultures and issue salience strong enough to generate meaningful boundaries and specific relational patterns even without taking identity processes into account.

\section{Identities and Field Boundaries}

In order to assess the structuring role of identities and recognize their relational dimension, we looked at how civic organizations define themselves, and are defined, as part of broader fields. We also explored how the two definitions combine. Externally defined identities refer to the classification of local organizations into types, associated with their major focus of activity: environment, ethnic minorities and migrants, community, and social exclusion (see table 1). This was generated by the research team in consultation with several local informants and by drawing upon scholarly literature as well as local directories. The exercise has obvious limitations, including the limited numbers involved in the consultation (see details in note 7), or the lack of data on how these organizations were represented in the media. Nonetheless, we still feel that the combination of input from academics, senior officers of voluntary sector coordinating bodies, and other local informants, with the categorizations generated by local and other public authorities, through their directories, is an adequate reflection of how civic organizations were perceived by relevant public actors.

As for actors' self-defined identities, we asked our respondents whether they regarded themselves as ethnic or environmental organizations, but also whether they felt part of an ethnic or environmental movement. For both Glasgow and Bristol, we included those identifying themselves as ethnic associations and environmental associations. We also included among self-defined ethnic associations those who claimed the objective of reaching their own ethnic group. On the other hand, claims expressing one organization's aspiration to reach ethnic minorities in general were considered instances of self-definition as ethnic and migrants' organizations only if they came from organizations that also referred explicitly to ethnic traits. As a result, some "white" charities promoting minorities' integration in general, or some "white" antiracist organizations were not considered as self-defined ethnic and migrant organizations.

We then looked for instances of symmetric identities, by which we mean those cases in which external and self-identities matched. In both cities, this was far from the majority of cases (see table 3). There were instead usually discrepancies between external and selfdefined identities that were particularly strong in the case of ethnic and migrants' organizations. In Glasgow, 16 organizations had a symmetric ethnic and migrants' identity while 36 did not; in Bristol, the ratio was almost identical, 12 vs. 25 . By contrast, 13 environmental organizations in Glasgow had a symmetric environmental identity vs. only 8 that did not, whereas in Bristol the figures were even more striking, with 32 symmetric and 14 asymmetric definitions of environmental identity. ${ }^{15}$

These distributions suggest that the environment operated as a source of collective identity in a more clear-cut way than ethnicity. For more than half of the organizations identifying themselves, or being identified, as environmental, the external definition matched the selfdefinition. Was this impression also confirmed by differences in relational patterns, eventually across different political contexts? Let us look first at the role of organizations' self-definitions (see table 4). In both cities, those that regarded themselves as environmentalist were significantly more likely to work with each other. In Glasgow, an environmental identity proved salient within civic networks, while environmental interests were not; in Bristol, alliances showed a much stronger relation to environmentalist identity than to interest in environmental issues, with the odds of a relation rising from 6.6 to 34.8 (see tables 2 and 4). Furthermore, the fact 
Table 3. Externally Defined, Self-defined, and Symmetric Identities as Environmental and as Ethnic and Migrants' Organizations (raw numbers)

\begin{tabular}{lcc}
\hline \hline & Glasgow & Bristol \\
\hline Environmental Identity & & 3 \\
External definition & 7 & 11 \\
Self-definition & 1 & 32 \\
Symmetric definition & 13 & 46 \\
$\mathrm{~N}$ & 21 & \\
\hline Ethnic and Migrants' Identity & & 12 \\
External definition & 18 & 13 \\
Self-definition & 18 & 12 \\
Symmetric definition & 16 & 37 \\
$\mathrm{~N}$ & 52 & \\
\hline \hline
\end{tabular}

that self-defined identities in reference to ethnic or migrant groups did not facilitate alliances in any way further confirms the greater salience of environmental identities. In both cities, the odds of an alliance between organizations sharing ethnic or migrants' identities were low, and the relationship not significant. This is particularly interesting in Glasgow, where in contrast ethnic and migrant interests actually had a structuring role (see table 2).

The picture changes once again if we look at "symmetric" identities, in which external and self-defined identities match (see table 5). By this more stringent criterion, both environmental and ethnic and migrant identities turned out to have a significant impact on the probability of an alliance and therefore on the composition of organizational fields. However, consistent with what we found for self-definitions, the environmentalist identity had the strongest impact in both cities. In Glasgow, the odds of a tie were 10.3, in comparison to odds of 6.6 for a link between organizations sharing an ethnic and migrant identity; in Bristol, the difference was even more pronounced, with odds of 44.1 in the former case, and 6.9 in the latter.

Table 4. Alliance Ties among Organizations with Different Self-defined Identities (observed/ expected ratios in brackets)

\begin{tabular}{|c|c|c|c|c|}
\hline \multirow[t]{2}{*}{ Environmental Identity } & \multicolumn{2}{|c|}{ Glasgow } & \multicolumn{2}{|c|}{ Bristol } \\
\hline & Without & With & Without & With \\
\hline Without environmental identity & $\begin{array}{c}264 \\
(.95)\end{array}$ & $\begin{array}{c}47 \\
(1.32)\end{array}$ & $\begin{array}{c}131 \\
(1.09)\end{array}$ & $\begin{array}{c}27 \\
(.47)\end{array}$ \\
\hline \multirow[t]{2}{*}{ With environmental identity } & $\begin{array}{c}23 \\
(.65)\end{array}$ & $\begin{array}{c}18 \\
(4.29)\end{array}$ & $\begin{array}{c}18 \\
(.31)\end{array}$ & $\begin{array}{c}86 \\
(3.24)\end{array}$ \\
\hline & Odds ratio 8.9 & $\mathrm{p}=.000$ & Odds ratio 34.8 & $\mathrm{p}=.000$ \\
\hline \multirow[t]{2}{*}{ Ethnic and Migrants Identity } & \multicolumn{2}{|c|}{ Glasgow } & \multicolumn{2}{|c|}{ Bristol } \\
\hline & Without & With & Without & With \\
\hline Without ethnic and migrants' identity & $\begin{array}{c}184 \\
(1.00)\end{array}$ & $\begin{array}{c}58 \\
(.82)\end{array}$ & $\begin{array}{c}183 \\
(1.06)\end{array}$ & $\begin{array}{c}31 \\
(.77)\end{array}$ \\
\hline \multirow[t]{2}{*}{ With ethnic and migrants' identity } & $\begin{array}{c}79 \\
(1.12)\end{array}$ & $\begin{array}{c}31 \\
(1.20)\end{array}$ & $\begin{array}{c}33 \\
(.82)\end{array}$ & $\begin{array}{c}15 \\
(1.70)\end{array}$ \\
\hline & Odds ratio 0.9 & $\mathrm{p}=.502$ & Odds ratio 2.5 & $\mathrm{p}=.094$ \\
\hline
\end{tabular}

Note: $\mathrm{N}=134$ in Bristol; $\mathrm{N}=124$ in Glasgow. 
Table 5. Alliance Ties among Organizations with Symmetric Identity Definitions (observed/ expected ratios in brackets)

\begin{tabular}{|c|c|c|c|c|}
\hline \multirow[t]{2}{*}{ Environmental identity } & \multicolumn{2}{|c|}{ Glasgow } & \multicolumn{2}{|c|}{ Bristol } \\
\hline & Without & With & Without & With \\
\hline Without symmetric environmental identity & $\begin{array}{c}267 \\
(.95)\end{array}$ & $\begin{array}{c}47 \\
(1.41)\end{array}$ & $\begin{array}{c}148 \\
(.98)\end{array}$ & $\begin{array}{c}32 \\
(.67)\end{array}$ \\
\hline \multirow[t]{2}{*}{ With symmetric environmental identity } & $\begin{array}{c}21 \\
(.63)\end{array}$ & $\begin{array}{c}17 \\
(4.72)\end{array}$ & $\begin{array}{c}15 \\
(.31)\end{array}$ & $\begin{array}{c}67 \\
(4.59)\end{array}$ \\
\hline & Odds ratio 10.3 & $\mathrm{p}=.000$ & Odds ratio 44.1 & $\mathrm{p}=.000$ \\
\hline \multirow[t]{2}{*}{ Ethnic and migrants identity } & \multicolumn{2}{|c|}{ Glasgow } & \multicolumn{2}{|c|}{ Bristol } \\
\hline & Without & With & Without & With \\
\hline $\begin{array}{l}\text { Without symmetric ethnic and migrants' } \\
\text { identity }\end{array}$ & $\begin{array}{c}279 \\
(1.05)\end{array}$ & $\begin{array}{l}31 \\
(.78)\end{array}$ & $\begin{array}{c}224 \\
(1.03)\end{array}$ & $\begin{array}{l}18 \\
(.84)\end{array}$ \\
\hline \multirow[t]{2}{*}{$\begin{array}{l}\text { With symmetric ethnic and migrants' } \\
\text { identity }\end{array}$} & $\begin{array}{l}26 \\
(.65)\end{array}$ & $\begin{array}{c}16 \\
(2.89)\end{array}$ & $\begin{array}{l}14 \\
(.65)\end{array}$ & $\begin{array}{c}6 \\
(3.09)\end{array}$ \\
\hline & Odds ratio 6.6 & $\mathrm{p}=.007$ & Odds ratio 6.9 & $\mathrm{p}=.028$ \\
\hline
\end{tabular}

Note: $\mathrm{N}=134$ in Bristol; $\mathrm{N}=124$ in Glasgow.

These findings do not suggest any relation between opportunity structures, political cultures, and the salience of different forms of identity. There may be fewer organizations identifying or being identified as environmentalist in cities where the class cleavage is still salient, like Glasgow, than in cities like Bristol where this cleavage has been largely pacified. However, that does not translate in relational patterns. These seem to be driven mainly by similarities in identities, regardless of the properties of the context in which they are located. To begin with, the salience of both environmental and ethnic identities runs counter to the expectation that the presence of institutional channels of access should correspond to a modest capacity of identities to shape civic networks. While the stronger impact of environmental identities casts doubts on the possibility that the overall growing relevance of environmental and ethnic and migration problems in public policy agendas corresponds to a similar salience of both environmental and ethnic and minority identities, at the same time, no significant differences could be found between cities on this ground. Neither did we find evidence suggesting that open opportunities of institutional access render identities less salient.

Summarizing our results on identities, the only instance of variation referred to types of identities rather than cities, as ethnic and migrant identities seemed to have a structuring effect only when they were symmetric - that is, when self-definitions were reciprocated by external definitions. In general, for all its vagueness, environmental identity seemed to provide a firmer point of identification. Although even environmental organizations may substantially differ in their orientations (Rohrschneider and Dalton 2002; Rootes 2003), in the early 2000s in Britain it was difficult to think of lines of differentiation among them as deep as those that kept organizations mobilizing for ethnic minorities apart on religious or cultural grounds. In the case of environmentalism, mere self-identification as environmentalist was sufficient to affect exchanges given the greater inclusiveness of this type of identity. ${ }^{16}$ While organizations mobilizing for ethnic minorities might in principle generate stronger feelings than environmental ones given their direct reference to strong identifiers as tradition, kin, history, ethnic traits, and so forth, this does not necessarily translate into an inclination to interact with organizations holding identities that refer to other ethnic, kin, and/or historical legacies. Identity at the organizational level may be strong, but identification with the ethnic and migrant sector may be weak because different ethnic groups may not share any common ideal, objective, or value. On the contrary, they may even reflect divisions and separations because of diverse tra- 
ditions, religions, or other cultural traits. There may even be a negative relation between the two: in other words, the depth of the embeddedness of most ethnic and migrant identities in specific collective experiences, cultural models, historical narratives, etc. may be precisely the factor that prevents many organizations from establishing privileged ties to other organizations holding analogous, yet substantively different, sources of recognition. At the same time, it is also worth emphasizing that, even in the case of ethnicity and migration, it might be possible to subscribe to a broader identity encompassing several organizations and groups, as shown by panethnic identities and mobilization among Asian-Americans (Okamoto 2003), and having one's alliances affected by such broader identification - for example, in relation to shared aspirations to human and/or citizenship rights.

For organizations mobilizing for ethnic minorities, the observed mechanisms operated only for symmetric identities. The presence of a symmetric identity meant that the nature of one organization as ethnic and/or migrant was supported by external recognition. In other words, symmetric identities referred to the most publicly visible organizations, the ones most easily identified as part of a sector, whose boundaries were more vague than others'. It is not surprising that this smaller set of organizations had stronger awareness of the potential for collaboration between organizations operating in a publicly recognized space, if possibly on behalf of different ethnic groups, and that the chance of denser interaction within that group (and therefore the presence of a "field") were likewise higher.

\section{DISCUSSION AND CONCLUSIONS}

To date, the study of movement organizational fields has been affected by a pronounced duality. On the one hand, ethnographic studies of specific populations (see, for example, Lichterman 1995; Bernstein 1997; Ray 1999; Armstrong 2002, 2005) have taught us a lot about how identities are constructed, boundaries established, and the reasoning of actors in their alliance building, but little about systematic patterns of exchange between those actors. On the other hand, analysts of interorganizational networks have started from a conventionally accepted view of field boundaries and moved on to explore the relations between field members as well as other dynamics of substantive interest without paying too much attention to how boundaries are constituted (see Diani 1995; Ansell 2003).

In this article, we have proposed a relational view of boundary definition, looking at how actors' interests and identities shape patterns of interorganizational relations. These two aspects of categorization processes need to be looked at in their interaction if we are to better grasp the properties of civic networks. Focusing on two cities with different political cultures and cleavages has enabled us to explore a number of theoretically plausible relationships between sociopolitical context and the salience of interests and/or identities over network patterns. In doing so we have added to the still relatively scarce attempts to look at how political opportunities and political culture affect relational processes and not just the behavior and/or the characteristics of the individuals or organizations involved in collective action.

In general, our analysis provides robust empirical support to the expectations, derived from both social movement and organizational theory (Melucci 1995; DiMaggio 1997; Fligstein 2001; Armstrong 2002, 2005), that identities are central in the definition of field boundaries. In particular, symmetric identities, implying the reciprocal recognition of actors, turn out to shape the structure of civic networks consistently across city and issue. At the same time, not all identities operate in the same way: in the case of environmentalism, organizations' self-definitions suffice to predict interaction between likes. In contrast, it is only when an organization's definition as ethnic or migrants' resonates with classifications by external observers that interactions with organizations holding similar identities are more likely. Here it is the public recognition that affects organizational identities and defines the boundaries of the field - better, to constitute the field. For all its vagueness, environmentalism 
seems to provide a sufficient number of shared symbols to provide a common ground for different organizations to meet. That this does not happen for ethnic and migrants' organizations might be the simple reflection of their acting on behalf of very distinctive, and sometimes mutually hostile, constituencies. However, the possibility of a broader, encompassing identity, bringing together multiple groups around an agenda of human rights, social inclusion, and multiculturalism, could not be ruled out in principle. That this does not happen, or, better, that it happens only for those organizations with a symmetric identity, calls for more fine grained analyses of the structure of specific identities and the factors that may alter their levels of inclusiveness or exclusiveness. That organizational fields are characterized by organizations that recognize each other and are recognized under a same label holds in both cities. As a consequence, our expectations about the mediating role of political structures and cultures are only partially confirmed.

It seems appropriate to close by locating our findings in their proper intellectual context, and acknowledging some of its obvious limitations. The first and most obvious shortcoming has to do with ours being a paired comparison (Tarrow 2010), which implies a limited number of cases by comparison to the number of theoretically relevant dimensions. Had we been able to draw on more cases we might have, for instance, also explored the impact of differences in the socioeconomic profile of contexts over boundary definition. We might have also tried to disentangle the effect of socioeconomic variables from that of local political cultures and political opportunities. As it happened, socioeconomic profiles and political cultures overlapped in our two cities, which prevented us from pursuing a broader range of theoretically possible lines of exploration.

We also have to admit that our measures of identity are very simple, and that future studies along the same lines will have to pay greater attention to the conceptualization of what represents a process of external, symmetric, and self-identification. We are convinced that bringing into the analysis how relevant observers - in particular, researchers - define civic organizations is a significant contribution in its own right. At the same time, we should pay greater attention to the role of other actors, primarily the media and key political actors, in shaping external representations of voluntary organizations. If other actors' perceptions of organizations indeed do affect their alliance building, then representations coming from more influential and more easily accessible actors than academics or voluntary sector officers should definitely be taken into account. One should also conduct systematic analyses of organizations' documents - not only of a written form - and other cultural artifacts in order to better grasp their representations of themselves as well as of other relevant alters (Donati 1992; Johnston 2002). We also need to identity more sophisticated measures that enable us to fully capture the difference between identities associated with specific organizations and identities referring to broader collectivities, including social movements.

Finally, for all the empirical overlaps between the two concepts, we have to remember that this is a study of boundaries of organizational fields, not of boundaries of social movements. While social movements can be read as organizational fields, the reverse does not always apply. We can have densely interacting organizations, setting clear relational boundaries within broader organizational populations, and still not have a social movement process in place. Exploring how social movements emerge out of larger sets of organizations is made even more difficult by the current variation in conceptualizations of social movements. While the most accepted definition stresses the role of "sustained interactions between challengers and powerholders" (Tilly 1978), yet without paying specific attention to organizations and organizational populations, others have focused on the network dimension of social movements (Diani 1992; Saunders 2007), and still others have emphasized the combination of protest repertoires and informality that makes movement organizations distinctive (Kriesi 1996). This renders the task of identifying the boundaries of social movements particularly complex, and worthy of a specific exploration, which goes well beyond the limits of the present article. 


\section{NOTES}

${ }^{1}$ The reverse does not apply: social movements are just one instance of organizational fields among innumerable others

${ }^{2}$ See Rowley and Moldoveanu (2003) for an account of mobilization processes similarly focused, if from a different analytic angle, on the interplay of interests and identity.

${ }^{3}$ Polletta and Jasper define identity as "an individual's cognitive, moral, and emotional connection with a broader community, category, practice, or institution" (2001: 285).

${ }^{4}$ For the sake of clarity, from now on we will only refer to external and self-defined identities.

${ }^{5}$ The importance of political cleavages has also been emphasized by the migration literature, advancing the notion that alliances among ethnic organizations seems to be primarily relevant in national political contexts, such as the Dutch one, where the social organization around ethnicity is promoted by multicultural policies (Fennema and Tillie 2004). In contrast, in contexts where the ethnic particularities are not recognized, like the Swiss or Italian political contexts, alliances among organizations mobilizing for ethnic minorities are fewer and migrant organizations are often linked to native organizations dominating the field of immigration (Eggert 2011; Pilati forthcoming).

${ }^{6}$ A citywide survey of the Glaswegian voluntary and community sector, conducted at the same time of our project, estimated about 1,800 voluntary organizations there (Smith et al. 2004). In Bristol, the umbrella organization VOSCUR - Voluntary Organisations Standing Council on Urban Regeneration-listed over 650 member organizations in the mid-2000s, and was by no means exhaustive of all organizations in the city (Bull and Jones 2006).

${ }^{7}$ Between September 2000 and March 2001, the senior author conducted seven interviews in Glasgow (with one academic, two community activists, and four senior officers of umbrella organizations for the voluntary sector) and eight interviews in Bristol (with three academics, three community activists, and two senior officers of umbrella organizations). These contributed to the identification of the relevant players in the local voluntary and community sectors from which we started the interview process. See Laumann and Knoke (1987) for a major example of case selection based on reputation.

${ }^{8}$ Although many more organizations were mentioned (over 500 in either city), none of them received more than three nominations. Only one interview was refused in Bristol, by an ethnic organization that at the time was in the midst of a serious - if temporary—organizational crisis.

${ }^{9}$ For example, one monthly meeting between a neighborhood environmental group and a major environmental association may be a strong tie for the former but a weak tie for the latter.

${ }^{10}$ In any case, we replicated the analyses presented in the following pages using only strong ties, which we defined as those coupling exchanges of resources on joint projects and shared core members (Baldassarri and Diani 2007). The results - available on request from the senior author - did not change at all.

${ }^{11}$ In this section we use the remote past tense not to imply that the city profiles we describe are necessarily obsolete, but more simply to firmly locate our discussion within a specific time frame.

${ }^{12}$ The local statistics reported in this article are from the 2001 UK Census and are available at www.statistics. gov.uk/Census2001. In 2001, Bristol counted 380,000 residents, while Glasgow counted 630,000.

${ }_{13}$ Our study is explorative and we purely focus on the impact that interests and identities have on field boundaries as well as the mediating role of the local political context. Yet, other factors may be taken into account in future analyses. For instance, different organizations' power positions and resource endowments may affect the modalities of alliances and field boundaries. Dominant and more powerful organizations and actors may have interests and views reflected in the organization of the field and thus affect the way alliances are structured (Fligstein and McAdam 2011: 3-4). See the essays collected in van Dyke and McCammon (2010) for a full exploration of the range of factors behind alliance building.

${ }^{14}$ The two lists correspond to the variables with a load of .5 or above on the corresponding components, which Diani (2005: 53-54) identified alongside with three others when looking at the correlations between 49 different subthemes (see also table 1). The Cronbach's Alphas for the two scales are .900 and .833 respectively.

${ }^{15}$ Eggert and Giugni's study of ethnic and migrant associations in different European cities (2010) shows that of the 617 organizations classified by researchers as such, only 42 percent actually defined themselves as migrants, and 22 percent as ethnic. Taking overlaps into account, this suggests about 50 percent of nonsymmetric definitions of identity.

${ }^{16}$ See also Armstrong $(2002,2005)$ on the role of inclusive identities in facilitating broader and more inclusive patterns of collaboration. The stronger correlation between environmental identity and interest in environmental issues might have also played a role. Contingency coefficients for the relationship between environmental identity and interest in environmental issues are .308 in Glasgow and .476 in Bristol, whereas those for ethnic identity and ethic interests are .274 in Glasgow and .099 in Bristol.

\section{REFERENCES}

Anderson, Jon. 2004. "Spatial Politics in Practice: The Style and Substance of Environmental Direct Action." Antipodes 36: 106-25.

Ansell, Chris. 2003. "Community Embeddedness and Collaborative Governance in the San Francisco Bay Area Environmental Movement.” Pp. 123-44 in Social Movements and Networks, edited by Mario Diani and Doug McAdam. New York: Oxford University Press. 
Armstrong, Elizabeth. 2002. Forging Gay Identities: Organizing Sexuality in San Francisco, 1950-1994. Chicago, IL: University of Chicago Press.

. 2005. "From Struggle to Settlement: The Crystallization of a Field of Lesbian/Gay Organizations in San Francisco, 1969-1973." Pp. 161-87 in Social Movements and Organization Theory, edited by Gerald Davis, Doug McAdam, Richard Scott, and Mayer N. Zald. New York: Cambridge University Press.

Baldassarri, Delia, and Mario Diani. 2007. "The Integrative Power of Civic Networks." American Journal of Sociology 113: 735-80.

Bernstein, Mary. 1997. "Celebration and Suppression: The Strategic Uses of Identity by the Lesbian and Gay Movement." American Journal of Sociology 103: 531-65.

Blau, Peter. 1977. "A Macrosociological Theory of Social Structure." American Journal of Sociology 83: 26-54.

Borgatti, Steven, Martin Everett, and Linton Freeman. 2002. Ucinet 6 for Windows: Software for Social Network Analysis. Boston, MA: Analytic Technologies.

Bourdieu, Pierre. 1994. Raison pratiques, sur la théorie de l'action sociale. Paris: Seuil.

Breiger, Ronald, and John Mohr. 2004. "Institutional Logics from the Aggregation of Organizational Networks: Operational Procedures for the Analysis of Counted Data." Computational \& Mathematical Organization Theory 10: 17-43.

Brubaker, Rogers, and Frederick Cooper. 2000. "Beyond identity." Theory and Society 29: 1-47.

Bull, Anna Cento, and Bryn Jones. 2006. "Governance and Social Capital in Urban Regeneration: A Comparison between Bristol and Naples." Urban Studies 43: 767-86.

Crossley, Nick. 2002. Making Sense of Social Movements. Buckingham: Open University Press.

Curtis, Russell L., and Louis A. Zurcher, Jr. 1973. "Stable Resources of Protest Movements: The Multiorganizational Field.” Social Forces 52: 53-61.

Dalton, Russell. 1994. The Green Rainbow. New Haven, CT: Yale University Press.

DiMaggio, Paul. 1997. "Culture and Cognition.” Annual Review of Sociology 23: 263-87.

DiMaggio, Paul, and Walter Powell. 1991. "The Iron Cage Revisited: Institutional Isomorphism and Collective Rationality in Organizational Fields." Pp. 63-82 in The New Institutionalism in Organizational Analysis, edited by Walter W. Powell and Paul J. DiMaggio. Chicago, IL/London: University of Chicago Press.

Diani, Mario. 1992. "The Concept of Social Movement." Sociological Review 40: 1-25. . 1995. Green Networks. Edinburgh: Edinburgh University Press.

- Forthcoming. "Organizational Fields and Social Movement Dynamics." In Advancements in Social Movement Research, edited by Bert Klandermans, Conny Roggeband, and Jacqueline Van Stekelenburg. Minneapolis, MN: University of Minnesota Press.

Diani, Mario, and Ivano Bison. 2004. "Organization, Coalitions, and Movements." Theory and Society 33: 281-309.

Donati, Paolo R. 1992. "Political Discourse Analysis." Pp. 136-67 in Studying Collective Action, edited by Mario Diani and Ron Eyerman. Newbury Park/London: Sage.

Eggert, Nina. 2011. The Impact of Political Opportunity Structures on Networks of Immigrant Associations: A Comparison of Two European Cities. PhD thesis, Universites of Geneva and of Trento.

Eggert, Nina, and Marco Giugni. 2010. "The Impact of Political Opportunity Structures on Organizational Characteristics and Activities: A Comparative analysis of Immigrants' Organizations." Paper for the workshop Social Capital and Political Participation by Migrants in European Cities. GERME-ULB, Brussels, November 5.

Ellemers, Naomi, Russell Spears, and Bertjan Doosje. 2002. "Self and Social Identity." Annual Review of Psychology 53: 161-86.

Fennema, Meindert, and Jean Tillie. 2004. "Do Immigrant Policies Matter? Ethnic Civic Communities and Immigrant Policies in Amsterdam, Liège and Zurich." Pp. 85-106 in Citizenship in European Cities. Immigrants, Local Politics and Integration Policies, edited by Rinus Penninx, Karen Kraal, Marco Martiniello, and Steven Vertovec. Aldershot: Ashgate.

Fligstein, Neil. 2001. "Social Skill and the Theory of Fields." Sociological Theory 19: 105-25.

Fligstein, Neil, and Doug McAdam. 2011. "Toward a General Theory of Strategic Action Fields." Sociological Theory 29: 1-26.

Gilchrist, Alison. 2000. The Well-Connected Community: A Networking Approach to Community Development. Bristol: Policy Press.

Gulati, Ranjay, and Martin Gargiulo. 1999. “Where Do Interorganizational Networks Come From?” American Journal of Sociology 104: 1439-93. 
Hanneman, Robert A., and Mark Riddle. 2005. Introduction to Social Network Methods. Riverside, CA: University of California, Riverside. Retrieved June 20, 2011 (http://faculty.ucr.edu/ hanneman/).

Henson, Manuel. 2003. "Social Movement Organizations: A Metaphor for Strategic Actors in Institutional Fields." Organization Studies 24: 355-81.

Hunt, Scott A., and Robert D. Benford. 2004. "Collective Identity, Solidarity and Commitment." Pp. 433-51 in The Blackwell Companion to Social Movements, edited by David A. Snow, Sarah A. Soule, and Hanspeter Kriesi. Oxford: Blackwell.

Hutchinson, John, and Anthony D. Smith (eds). 1996. Ethnicity. New York: Oxford University Press.

Johnston, Hank. 2002. "Verification and Proof in Frame and Discourse Analysis." Pp. 62-91 in Methods of Social Movement Research, edited by Bert Klandermans and Suzanne Staggenborg. Minneapolis: University of Minnesota Press.

Kriesi, Hanspeter. 1996. "The Organizational Structure of New Social Movements in a Political Context." Pp. 152-84 in Comparative Perspective on Social Movements: Political Opportunities, Mobilizing Structures, and Cultural Framing, edited by Doug McAdam, John McCarthy, and Mayer N. Zald. New York: Cambridge University Press.

Kriesi, Hanspeter, Ruud Koopmans, Jan-Willem Duyvendak, and Marco Giugni. 1995. New Social Movements in Western Europe: A Comparative Analysis. Minneapolis: University of Minnesota Press.

Lamont, Michele, and Virag Molnar. 2002. "The Study of Boundaries in the Social Sciences.” Annual Review of Sociology 28: 167-95.

Laumann, Edward O., and David Knoke. 1987. The Organizational State: Social Choice in National Policy Domains. Madison: University of Wisconsin Press.

Lawrence, Paul, and Jay Lorsch. 1967. Organizations and Environment. Boston, MA: Harvard Business School Press.

Lichterman, Paul. 1995. "Piecing Together Multicultural Community: Cultural Differences in Community Building among Grass-Roots Environmentalists.” Social Problems 42: 513-34.

Lomi, Alessandro, and Erik R. Larsen (eds). 2001. Dynamics of Organizations: Computational Modeling and Organization Theories. Cambridge, MA: MIT Press.

Lounsbury, Michael, Marc Ventresca, and Paul M. Hirsch. 2003. "Social Movements, Field Frames and Industry Emergence: A Cultural-Political Perspective on US Recycling.” Socio-Economic Review 1: 71-104.

Lowndes, Vivien, Lawrence Pratchett, and Gerry Stoker 2001. "Trends in Public Participation: Part 1Local Government Perspectives." Public Administration 79: 205-22.

Marsden, Peter V. 1990. "Network Data and Measurement." Annual Review of Sociology 16: 435-63.

. 2005. "Recent Developments in Network Measurement." Pp. 8-30 in Models and Methods in Social Network Analysis, edited by Peter Carrington, John Scott, and Stanley Wasserman. New York: Cambridge University Press.

Martin, John Levi. 2003. "What Is Field Theory?” American Journal of Sociology 109: 1-49.

McAdam, Doug, and Richard Scott. 2005. "Organizations and Movements." Pp. 4-40 in Social Movements and Organization Theory, edited by Gerald Davis, Doug McAdam, Richard Scott, and Mayer N. Zald. New York: Cambridge University Press.

McPherson, Miller, Lynn Smith-Lovin, and James M. Cook. 2001. "Birds of a Feather: Homophily in Social Networks." Annual Review of Sociology 27: 415-44.

Melucci, Alberto. 1989. Nomads of the Present. London: Hutchinson Radius.

- 1995. "The Process of Collective Identity." Pp. 41-63 in Social Movements and Culture, edited by Hank Johnston and Bert Klandermans. Minneapolis, MN: University of Minnesota Press.

Merton, Robert K. 1968. Social Theory and Social Structure. New York: Free Press.

Minkoff, Debra, and John McCarthy. 2005. "Reinvigorating the Study of Organizational Processes in Social Movements." Mobilization 10: 289-308.

Mische, Ann. 2003. "Cross-talk in Movements: Reconceiving the Culture-Network Link." Pp. 258-80 in Social Movements and Networks, edited by Mario Diani and Doug McAdam. New York: Oxford University Press.

Modood, Tariq. 2005. Multicultural Politics. Edinburgh: Edinburgh University Press.

Mohr, John.W., and Vincent Duquenne. 1997. "The Duality of Culture and Practice: Poverty Relief in New York City, 1888-1917." Theory and Society 26: 305-56.

Okamoto, Dina. 2003. "Toward a Theory of Panethnicity: Explaining Asian American Collective Action." American Sociological Review 68: 811-42.

Pfeffer, Jeffrey, and Gerald Salancik. 1978. The External Control of Organizations. New York: Harper and Row. 
Pilati, Katia. Forthcoming. "Network Resources and Political Engagement by Migrant Organizations in Milan." Journal of Ethnic and Migration Studies.

Pizzorno, Alessandro. 1996. "Decisioni o interazioni? La micro-descrizione del cambiamento sociale." Rassegna Italiana di Sociologia 37: 107-32.

Polletta, Francesca, and James M. Jasper. 2001. "Collective Identity and Social Movements." Annual Review of Sociology 27: 283-305.

Purdue, Derrick, Jörg Dürrschmidt, Peter Jowers, and Richard O'Doherty. 1997. "DIY Culture and Extended Milieux: LETS, Veggie Boxes and Festivals.” Sociological Review 45: 645-67.

Rao, Hayagreeva, Philippe Monin, and Rodolphe Durand. 2003. "Institutional Change in Toque Ville: Nouvelle Cuisine as an Identity Movement in French Gastronomy." American Journal of Sociology 108: 795-843.

Ray, Raka. 1999. Fields of Protest: Women's Movements in India. Minneapolis: University of Minnesota Press.

Rohrschneider, Robert, and Russell Dalton. 2002. “A Global Network? Transnational Cooperation among Environmental Groups." Journal of Politics 64: 510-33.

Rootes, Christopher. 2003. Environmental Protest in Western Europe. Oxford: Oxford University Press.

Rowley, Timothy, and Minhea Moldoveanu. 2003. "When Will Stakeholder Groups Act? An Interest and Identity Based Model of Stakeholder Group Mobilization." Academy of Management Review 28: 204-19.

Rytina, Steve, and David Morgan. 1982. "The Arithmetic of Social Relations: The Interplay of Category and Network." American Journal of Sociology 88: 88-113.

Saunders, Clare. 2007. "Using Social Network Analysis to Explore Social Movements: A Relational Approach." Social Movement Studies 6: 227-43.

Smith, Graham, William Maloney, and Gerry Stoker. 2004. "Building Social Capital in City Politics: Scope and Limitations at the Inter-organisational Level." Political Studies 52: 508-30.

Stryker, Sheldon, Timothy J. Owens, and Robert W. White (eds.). 2000. Self, Identity, and Social Movements. Minneapolis, MN: University of Minnesota Press.

Tarrow, Sidney. 2010. "The Strategy of Paired Comparison: Toward a Theory of Practice." Comparative Political Studies 43: 230-50.

Taylor, Marylin. 2003. Public Policy in the Community. Basingstoke: Palgrave Macmillan.

Tilly, Charles. 1978. From Mobilization to Revolution. Reading, MA: Addison-Wesley. . 2005. Identities, Boundaries and Social Ties. Boulder, CO: Paradigm.

Van Dyke, Nella, and Holly McCammon (eds). 2010. Social Movement Coalitions. Minneapolis: University of Minnesota Press.

Vermeulen, Floris. 2006. The Immigrant Organizing Process: Turkish Organizations in Amsterdam and Berlin and Surinamese Organizations in Amsterdam, 1960-2000. Amsterdam: IMISCOE Dissertations/Amsterdam University Press.

Wimmer, Andreas. 2008. "The Making and Unmaking of Ethnic Boundaries: A Multi-level Process Theory." American Journal of Sociology 113: 970-1022.

Zald, Mayer N. 2008. "Epilogue: Social Movements and Political Sociology in the Analysis of Organizations and Markets." Administrative Science Quarterly 53: 568-74. 